\title{
Study on nanocoated pet bottles of tomato puree against Enteropathogenic bacteria
}

\author{
M. Ramya ${ }^{1 *}$, M. Sylvia Subapriya ${ }^{1}$ and Nalini B ${ }^{2}$ \\ ${ }^{1}$ Department of Food Science and Nutrition, Avianshilingam Institute for Home Science and Higher Education for Women, Coimbatore, Tamilnadu, India \\ ${ }^{2}$ Department of Physics, Avianshilingam Institute for Home Science and Higher Education for Women, Coimbatore, Tamilnadu, India
}

\begin{abstract}
PET is globally recognized as safe, recyclable packaging, thermoplastic polymer, commonly used in beverage and food industries. It is a transparent, light-weight, strong, safe, shatterproof and recyclable packaging material with an inherent barrier used for wide range of product applications. The purpose of study is to assess the shelf-life of silver nanocoated (Glycyrrbiz aglabra) PET bottles of tomato puree for a period of ten days against enteropathogenic bacteria such as E. coli (MTCC40), Salmonella enteric (MTCC3219) and Shigella dysenteriae (PSGIMS \& R). The maximum inhibition of antimicrobial activity of silver nanoparticle coated PET bottles of tomato from 0th day to $10^{\text {th }}$ day, showed that 56.83 percentage against E. coli (MTCC 40), 67.67 and 87.67 percentage against Salmonella enteric (MTCC 3219) and Shigella dysenteriae (PSGIMS \& R) respectively. Hence, different food packages can be tried out with coatings of silver-nanoparticles which could improve the shelf-life and antimicrobial property of food packages.
\end{abstract}

\section{Introduction}

The global production of plastics would reach about 227MT by 2015, with a growth rate increase of about five percent per year. PET is thermoplastic polyester widely used for production of beverage bottles. Plastic bottles made from polyethylene terephthalate (PET) are increasingly used in storage of beverages like softdrinks, mineral water, juices and beer, in comparison to other packaging plastic.PET is considered to be the most inert of polymers with good barrier properties against moisture, oxygen and carbon dioxide with a low migration tendency of its constituents [1]. According to National Association for PET Container Resources (NAPCOR, 2011), among 5,478 million pounds of PET bottles are available for recycling [2]. Different technologies can further enhance PET inherent barrier properties and offer great protection to natural properties of packaged products against oxygen migration and carbon dioxide. Food packed into PET containers is the main source of microorganisms causing diarrheal diseases $[3,4]$. Hence technology to minimize microbial health hazards is the need of the hour. Therefore barrier enhanced technology such as nanoparticle coatings on PET bottles was tried out in this study.

\section{Materials and methods}

The methodology adopted for the present study, 'Antimicrobial and Shelf-life Study of Nanocoated PET Bottles of tomato puree against E. coli (MTCC 40), Salmonella enteric (MTCC 3219) and Shigella dysenteriae (PSGIMSR)', is as follows:

\section{Preparation of the plant powder and extract}

Fresh medicinal plants Glycyrrhiz aglabra were collected from Annaikatti Hills and were certified by Botanical Survey of India, Coimbatore. For the preparation of extract, $10 \mathrm{~g}$ of the plant powder was added to $100 \mathrm{ml}$ sterile distilled water in a $250 \mathrm{ml}$ Erlenmeyer flask and boiled for 5 mins. The boiled extract was filtered using three whatmann filter paper No.1. Further, the plant extract was subjected for synthesis of encapsulated silver nanoparticles.

\section{Biosynthesis of nano-scale silver particles}

The prepared medicinal plant extract of Glycyrrhiz aglabra was then centrifuged through GLC (1000 rpm for 45 minutes) and then added with $1 \mathrm{mM} \mathrm{AgNO}_{3}$. Further, the filtrate was centrifuged through ultracentrifuge for $1 \mathrm{hr} 10$ minutes. The nanoparticle solution was used for coating PET bottles.

\section{Preparation of tomato puree}

Fresh tomatoes (Solanum lycopersicum) were boiled with $1 / 2$ cup sugar and 1 tablespoon of salt. The puree was then stored in $100 \mathrm{ml}$ PET containers (with and without nanocoat).

\section{Testing highest antimicrobial activity of nanoparticles}

The PET bottles were punched out into disc size for performing agar well diffusion method for determining the highest activity among the different concentration of nanoparticles. The antimicrobial activity of synthesized silver nanoparticles was done by the agar diffusion method. The log phase cultures were spread over the Nutrient agar medium plates using a sterile cotton swab in order to get a uniform microbial growth on test plates. Then approximately four wells of uniform sizes $(0.65 \mathrm{~cm})$ were made with a cork-borer, tested with nanoparticle solution at $10 \mu \mathrm{l}, 20 \mu \mathrm{l}, 30 \mu \mathrm{l}, 40 \mu \mathrm{l}$ and other petri plate tested with $50 \mu \mathrm{l}, 75 \mu \mathrm{l}, 100 \mu \mathrm{l}$ and $125 \mu \mathrm{l}$ of the encapsulated silver colloids were pipetted directly into the well against the test organisms of E.coli (MTCC-40), Salmonella enteric (MTCC 3219) and Shigella dysenteriae (PSGIMS \& R). The plates were were incubated at $37^{\circ} \mathrm{C}$ for 24-48 hours.

Correspondence to: M. Ramya, Department of Food Science and Nutrition, Avianshilingam Institute for Home Science and Higher Education for Women, Coimbatore, Tamilnadu, India, E-mail: ramvindrheya@gmail.com

Received: March 28, 2015; Accepted: April 25, 2015; Published: April 29, 2015 


\section{Shelf-life study of nanocoated PET bottles with tomato puree}

Further, PET bottles were made sterile under UV light, by swab method highest activity of freshly prepared nanoparticle solution were coated by swabbing and dried under the Laminar flow chamber for 40 minutes. After drying, the PET bottles were packed with tomato puree and inoculated with the test organism (in duplicates) E. coli (MTCC-40), Salmonella enteric (MTCC3219), Shigella dysenteriae (PSGIMS \& $R$ ) and control (without nanocoating), tested for storage period of 10 days. For every two days interval, the sample was tested for enumeration of microbes.

\section{Results and discussions}

\section{Highest antimicrobial activity of nanoparticle solution}

Figures $1 \mathrm{~A}, 1 \mathrm{~B}$ and $1 \mathrm{C}$ present microbial activity of the three microbes against different concentrations of nanocoats. IA, IB and IC by Agar well diffusion method, with nanoparticle solution at $10 \mu \mathrm{l}, 20$ $\mu \mathrm{l}, 30 \mu \mathrm{l}, 40 \mu \mathrm{l}, 50 \mu \mathrm{l}, 75 \mu \mathrm{l}, 100 \mu \mathrm{l}$ and $125 \mu \mathrm{l}$ of the silver colloids tested against E.coli (MTCC 40), Salmonella enteric (MTCC3219) and Shigella dysenteriae (PSGIMS \& R) showed that $30 \mu \mathrm{l}$ had a maximum zone of inhibition. Hence, $30 \mu \mathrm{l}$ was selected for coating the PET bottles.

From the Table 1, $30 \mu \mathrm{l}$ nanoparticle solution showed less count of E. coli (MTCC 40) 33 counts, S. enterica (MTCC3219) 48 counts and S. dysenteriae (PSGIMSR) 42 counts. Since $30 \mu$ nanoparticle solution

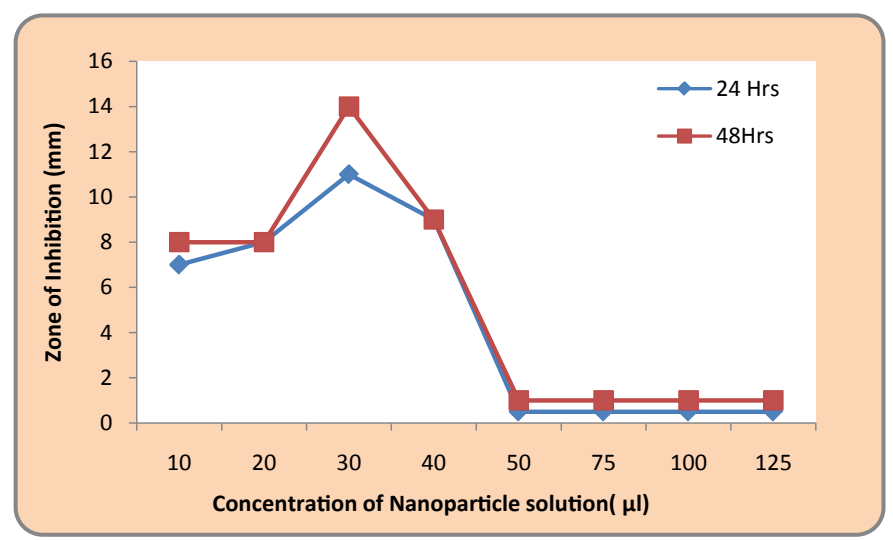

Figure 1a. Agar well diffusion (Glycyrrhiz aglabra) nanoparticle solution E. coli (MTCC 40).

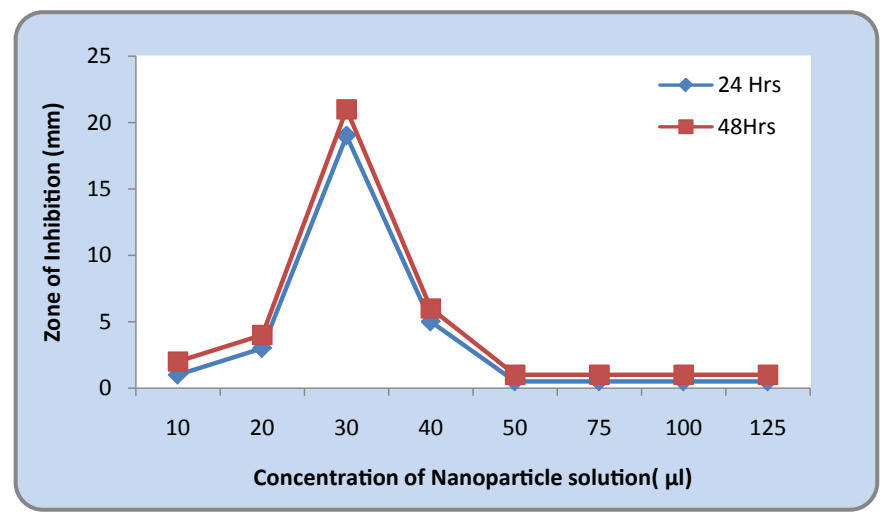

Figure 1b. Agar well diffusion (Glycyrrhiz aglabra) nanoparticle solution Salmonella enterica (MTCC 3219).

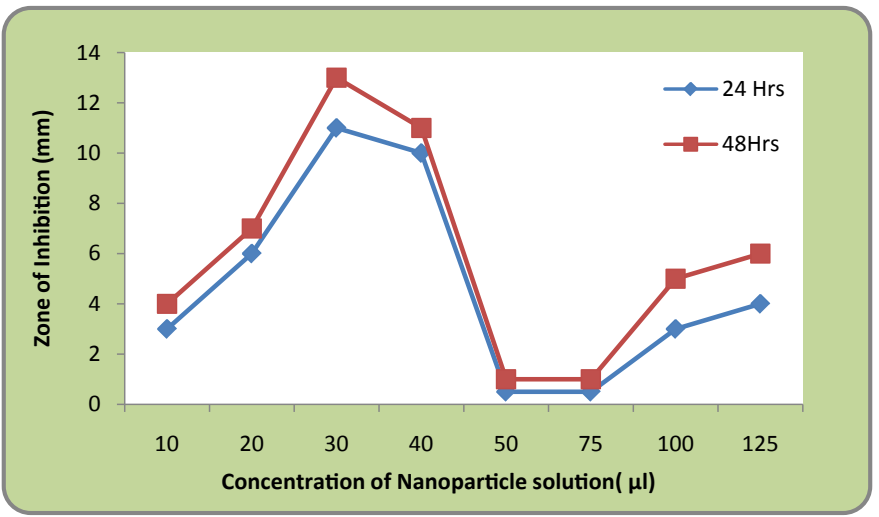

Figure 1c. Agar Well diffusion (Glycyrrhiz aglabra) nanoparticle solution Shigella dysetneriae (PSGIMSR).

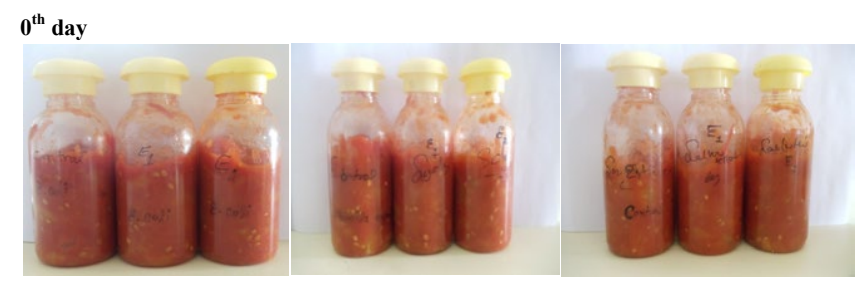

$10^{\text {th }}$ day

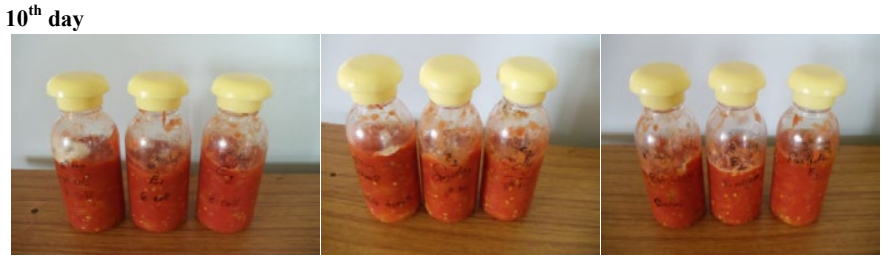

Figure 2. Nanocoated PET bottles with tomato puree (E. coli, S. enteric \& S. dysenteriae)

\begin{tabular}{|c|c|c|c|}
\hline $\begin{array}{c}\text { Concentration } \\
\boldsymbol{\mu} \mathbf{l}\end{array}$ & $\begin{array}{c}\boldsymbol{E} \text {. coli } \\
\text { (MTCC 40) }\end{array}$ & $\begin{array}{c}\text { S. enterica } \\
\text { (MTCC 3219) }\end{array}$ & $\begin{array}{c}\text { S. dysenteriae } \\
\text { (PSGIMSR) }\end{array}$ \\
\hline 10 & 36 & 80 & 55 \\
\hline 20 & 28 & 74 & 50 \\
\hline 30 & 23 & 48 & 42 \\
\hline 40 & 37 & 66 & 49 \\
\hline Control & 56 & 90 & 72 \\
\hline 50 & 54 & 72 & 61 \\
\hline 75 & 52 & 81 & 63 \\
\hline 100 & 47 & 83 & 58 \\
\hline 125 & 41 & 87 & 50 \\
\hline Control & 64 & 93 & 76 \\
\hline
\end{tabular}

Table 1. Enumeration of bacterial counts (Glycyrrhiz aglabra) nanoparticle solution.

showed maximum inhibition of microbial counts, $30 \mu \mathrm{l}$ nanoparticle solution was used for further shelf-life study

Figure 2 and 3, shown the Shelf-life Study of tomato puree for PET bottles is taken for a period of ten days. The enumeration of bacteria was done periodically once in every two days. It was found that $0^{\text {th }}$ day to $6^{\text {th }}$ day there was no difference in microbial growth of all three species. But $0^{\text {th }}$ day to $10^{\text {th }}$ day nanoparticle coated showed that $56.83 \%$ difference against $E$. coli (MTCC40), 67.67 and $87.67 \%$ against $S$. enterica (MTCC 3219) \& S. dysenteriae (PSGIMSR) respectively (Table 2).

\section{Conclusion}

The maximum inhibition of antimicrobial activity of silver 
0 days
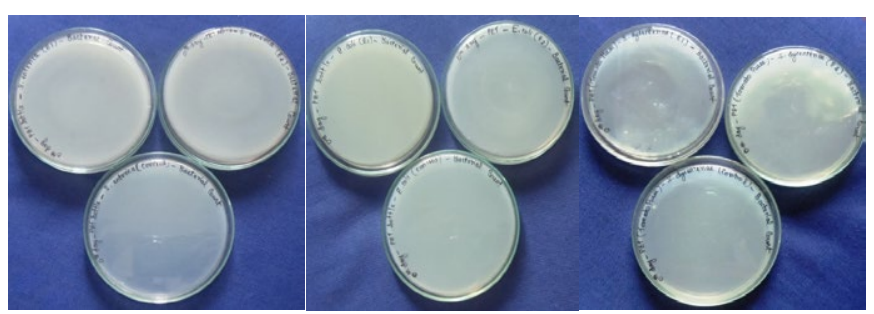

$6^{\text {th }}$ day
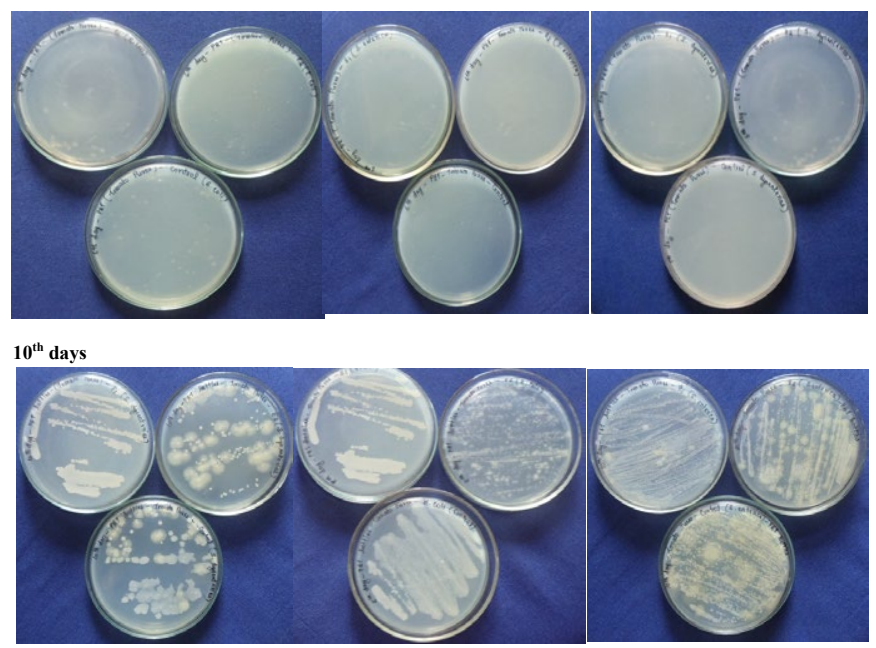

Figure 3. Shelf-life Study of tomato puree for PET bottles. Tomato Puree (E. coli, S enterica and $S$. dysenteriae).

Table 2. Shelf-life Study of Tomato Puree-PET Bottles.

\begin{tabular}{|c|c|c|c|c|c|c|c|c|c|}
\hline $\begin{array}{c}\text { Day of } \\
\text { Testing }\end{array}$ & \multicolumn{3}{|c|}{$\begin{array}{c}\text { E. coli } \\
\text { (MTCC 40) }\end{array}$} & \multicolumn{3}{c|}{$\begin{array}{c}\text { S. enterica } \\
\text { (MTCC 3219) }\end{array}$} & \multicolumn{3}{c|}{$\begin{array}{c}\text { S. dysenteriae } \\
\text { (PSGIMR) }\end{array}$} \\
\cline { 2 - 10 } & E1 & E2 & Control & E1 & E2 & Control & E1 & E2 & Control \\
\hline 0 & NIL & NIL & NIL & NIL & NIL & NIL & NIL & NIL & NIL \\
\hline 2 & NIL & NIL & NIL & NIL & NIL & NIL & NIL & NIL & NIL \\
\hline 4 & NIL & NIL & NIL & NIL & NIL & NIL & NIL & NIL & NIL \\
\hline 6 & NIL & NIL & NIL & NIL & NIL & NIL & NIL & NIL & NIL \\
\hline 8 & 46 & 50 & 113 & 89 & 93 & 162 & 24 & 27 & TNTC \\
\hline 10 & 128 & 131 & TNTC & 96 & 98 & TNTC & 38 & 36 & TNTC \\
\hline
\end{tabular}

nanoparticle coated in PET bottles of Tomato from $0^{\text {th }}$ day to $10^{\text {th }}$ day nanoparticle coated showed that $56.83 \%$ against E.coli (MTCC40), 67.67 and $87.67 \%$ difference against S. enteric (MTCC 3219) and S. dysenteriae (PSGIMSR) respectively. Feng et al. [5] stated that the microbial inhibition is due to effects of silver ions on gram-negative bacteria Escherichia coli, Salmonella and Shigella dysenteriae it was observed that microbial cells exposed to the $\mathrm{Ag}^{+}$ions poses stress which led to the condensation of DNA. Therefore, these plant extracts of silver nanoparticles could be used as a coating in food packages as a value addition increasing the shelf- life.

\section{References}

1. Welle F, Franz R (2011) Migration of antimony from PET bottles into beverages determination of the activation energy of diffusion and migration modelling compared with literature data. Food Addit Contam Part A Chem Anal Control Expo Risk Assess 28: 115-126. [Crossref]

2. National Association for PET Container Resources [NAPCOR](2011), E-Article from www.napcor.com

3. Fang TJ, Wei QK, Liao CW, Hung MJ, Wang TH (2003) Microbiological quality of 18 degrees $\mathrm{C}$ ready-to-eat food products sold in Taiwan. Int J Food Microbiol 80: 241-250. [Crossref]

4. Rabbani GH, Greenough WB 3rd (1999) Food as a vehicle of transmission of cholera. J Diarrhoeal Dis Res 17: 1-9. [Crossref]

5. Feng QL, Wu J, Chen GQ, Cui FZ, Kim TN, et al. (2000) A mechanistic study of the antibacterial effect of silver ions on Escherichia coli and Staphylococcus aureus. Journal of Biomedical Materials Research Part A 52: 662-668. [Crossref]

Copyright: (C2015 Ramya M. This is an open-access article distributed under the terms of the Creative Commons Attribution License, which permits unrestricted use, distribution, and reproduction in any medium, provided the original author and source are credited. 